\title{
A Closed-loop System of Construction and Demolition Waste Recycling
}

\author{
J. Brennan ${ }^{a}$, G. Ding ${ }^{b}$, C.-R. Wonschik ${ }^{c}$ and K. Vessalas ${ }^{a}$ \\ ${ }^{a}$ School of Civil Engineering, University of Technology Sydney, Australia \\ ${ }^{b}$ School of the Built Environment, University of Technology Sydney, Australia \\ ${ }^{c}$ Faculty of Automation and Computer Sciences, University of Applied Sciences, \\ Germany \\ Email: Jane.Brennan@uts.edu.au, Grace.Ding@uts.edu.au, rwonschik@hs-harz.de, \\ Kirk.Vessalas@uts.edu.au
}

\begin{abstract}
-
This study discusses the construction and demolition waste recycling stream both in Australia and in Germany. Differences and commonalities in commercial practices between the two countries are outlined, and open research questions are introduced. Following McDonough and Braungart's cradle-to-cradle theorem, and ideal closedloop system within the building life cycle is proposed. Deficiencies and efficiencies in the closed-loop system are reported and assessed and related parameters promoting or hindering the closed-loop system are evaluated. Results of the study demonstrate that reusable and non-reusable materials generated from construction and demolition operations, which are destined for landfill, are categorized differently between the recycling systems used in Australia and Germany.
\end{abstract}

Keywords -

Construction and Demolition Waste, Closed-loop system

\section{Introduction}

Worldwide building materials, which constitute approximately $50 \%$ of all used materials and of the solid waste generated, have considerable environmental impacts throughout the entire construction process [1]. In order to move towards more sustainable construction, it is necessary to create a material flow that returns as much as possible into the building life cycle. This paper proposes an ideal closed-loop system and investigates potential drivers for a more sustainable building life cycle. Since waste is a large component of the material flow, the following discussion will focus on construction and demolition (C\&D) waste which is often defined as "the solid component of the waste stream arising from the construction, demolition or refurbishment of buildings or infrastructure" ([2], p.3). It contains no ${ }^{1}$ foreign material in the case of inert C\&D waste or less than $25 \%$ foreign material in the case of mixed C\&D waste. C\&D waste includes "bricks, concrete, tiles and ceramics, steel and inert soils." ([2], P.3) Permissible foreign materials exclude "Municipal Solid Waste, Liquid, Listed, Hazardous or Radioactive Waste." ([2], p.3) Based on a case study on C\&D waste recycling in Australia and Germany, the ideal closedloop system was developed and potential drivers that could be used to move towards such an ideal system were investigated using figures from both countries.

The next section discusses challenges and drivers of C\&D waste before introducing the closed-loop system. A general discussion on commercial practices in C\&D waste recycling in Australia and Germany follows. There are two case studies, one for an Australian mixed C\&D waste recycling facility and one for a German (inert) C\&D waste recycling facility. In both cases the pricing structures are outlined and then compared in relation to general waste statistics to establish a rapport on the potential causes of different recycling rates.

\section{Challenges and Drivers of $C \& D$ waste recycling}

Waste is produced in different types and quantities throughout the life cycle of a building with the bulk of the waste being produced during the construction and demolition phases. The environmental problem posed by waste generated during the C\&D phases is not only from its increases in volume, but also from its method of treatment [3]. This process generates waste and this waste has caused a serious environmental problem. The figures generated for construction-related waste amount

${ }^{1}$ Less than $5 \%$ 
to approximately $30 \%$ in the US, $35 \%$ in Canada and $50 \%$ in the UK $[4,5,6]$. In Australia C\&D waste accounts for about $38 \%$ of the total waste generated in $2006 / 7$ and about $43 \%$ of C\&D waste went into landfill $[7,8]$. The waste is often generated due to an inefficient management onsite or workshop. Most of this waste can be recycled and reduced if properly planned and managed.

$\mathrm{C} \& \mathrm{D}$ waste minimisation is increasingly realised as an ecologically sustainable strategy in the construction industry as a way to ease the need for virgin materials, minimise the space and cost for the disposal of waste materials, and subsequently enhance efficient use of the materials [9].

Traditionally, waste produced during construction or demolition is considered as a homogenous by-product of the process. However this approach of handling C\&D waste represents a loss of opportunity as most of these wastes are not waste, but valuable resources if they are salvaged and separated properly [10]. Therefore recovering waste and keeping it separated offers significant economic benefits in the construction industry. It minimises the transportation and disposal costs for landfilling. In addition the salvaged materials generate economic benefits either by selling them for recycling, or by incorporation into future projects. However according to Marie and Quiasrawi [9] the current use of recycled C\&D wastes are largely downvalued as they are mostly used as hardcore or backfilling materials. Therefore proper management will need to be considered at the outset if the value of $\mathrm{C} \& \mathrm{D}$ waste is to be fully recognized.

Barriers and challenges have been well examined and addressed in research studies. The negative perceptions and unawareness for the usefulness of recycled materials in the construction industry has been the major hurdle for C\&D waste management. Osmani et al. [11] conducted a questionnaire survey to the top 100 architectural and contracting companies in the UK and realised that $C \& D$ waste management is not fully recognised and considered in the design process of a project. Yuan and Shen [12] suggest that concern about extra labour and equipment cost in collecting and sorting have been the key barrier to the recycling practices in construction.

Quality of recycled materials is another concern as it may be hampered by cross-contamination with other materials in the salvaging, collecting and storing process [13]. Asbestos contamination is a well-documented problem and the most common form of quality control is at the recycling yard for visual inspection. The lack of an industry-wide standard and material testing program to validate compliance to the prescribed standard are major problems for the C\&D waste.

As the range of products and materials increases there will be a vital need for training and education to provide greater awareness for the importance of waste materials, and knowledge of how to use them successfully in projects as alternatives to virgin materials. The perceptions will only be changed if more data for field trial show how to use these materials to their optimum performance. The lack of technology and equipment to sufficiently clean or segregate materials has caused significant volumes of materials being sent to landfill. There is a clear need for investment in research and development to overcome technological barriers.

Over the years, research and development in the minimisation of waste has gone underway and a waste management hierarchy has been well established. The waste management hierarchy builds on the principles of $3 R s$ and 5Rs. The principle of the C\&D waste management hierarchy is to reduce consumption of raw materials for environmental conservation along with the continued recycling and reusing of $C \& D$ waste. This principle allows and directs the construction activities to an environmentally-friendly process, therefore reducing the eventual material within landfill. The 3Rs principle in $\mathrm{C} \& \mathrm{D}$ waste management refers to reduce, reuse and recycle. It has significant impact on reducing the need to extract raw materials, reducing the amount of materials going to landfill sites and thus reducing the life-cycle costs of buildings and building materials. The $3 \mathrm{Rs}$ principle has further been developed into a 5Rs Rule where refuse and repair have been added into the hierarchy $[9,14]$.

Reuse of building materials deals with a serious resource issue. The reuse of materials involves the consideration of the material and joining techniques so as to enable the reuse and replacement of components, either in parts or as a whole. When the reuse of a component is not possible, it may still be possible to recycle it in whole or in parts. Reduce relates to the reduction in the use of resources, space or elements. It is not necessary to undermine a good design solution such as reducing the amount of mechanical services to suit. It involves the adaptation of existing buildings instead of demolition and reuse of salvaged materials to minimise raw material consumption. Refuse refers to setting guidelines on what are and are not acceptable materials in buildings. For example, the European Commission released the integrated product policy to identify products within the construction sector for products that have the greatest lifetime environmental impact potential. Repair is a strategy that aims to reduce a wasteful lifestyle by overhauling and refurbishing to 
extend the useful life.

\section{A closed-loop model for the C\&D waste stream}

Traditionally the use of construction materials is characterised by a linear process of extraction, manufacture, construction, maintenance and refurbishment, demolition, and disposal. However, in the last two decades there has been a shift in the construction industry from linear production and consumption of materials and products to some cyclic manufacturing activities [15]. Therefore, products and components used in construction should be designed in such a way to enable materials to maintain their status as resources. As such at their end of life cycle, materials are re-entered further into another life cycle in substitution of virgin materials [16].

This shift considers a closed-loop approach in C\&D waste management as an alternative to the traditional linear process. The closed-loop approach allows materials and components to be reclaimed, reused and recycled multiple times during the life-cycle. The closedloop approach in $C \& D$ waste management plays a significant role in achieving the goal of sustainable construction as it aims at closing material life-cycle loops where waste from one process will be the resource for another. Figure 1 presents the model of linear and closed-loop system in C\&D waste management.

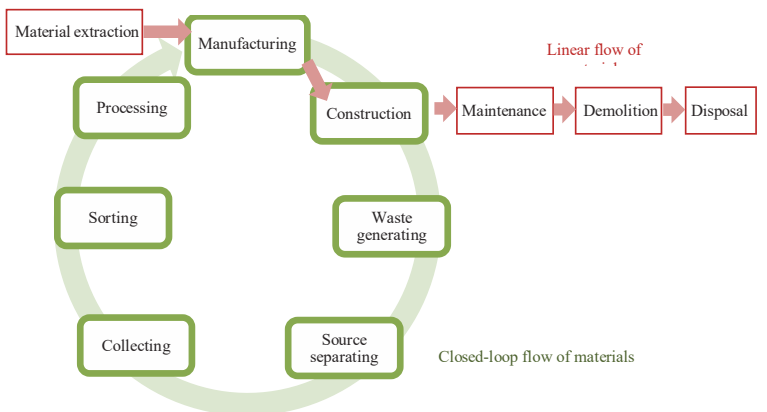

Figure 1. Linear and closed-loop model of C\&D waste

The traditional linear value chain allows valuable C\&D waste to end up in landfill and impact on the environment. However the closed-loop approach utilises the 5 Rs principle by closing the material life-cycle loop.

The concept of cradle-to-cradle and zero waste is the heart of the closed-loop waste management system. It is related to product design and builds on the idea of ecoefficiency of materials with the aim of reducing the consumption of virgin resources and eliminating waste and pollution [15]. In principle materials are extracted from buildings and reintegrated directly or reprocessed and then reintegrated into buildings or put to useful purpose in other sectors without creating any waste. According to Sassi [17] the principle of the closed-loop approach would include the ability to be reprocessed infinitely through industrial or natural recovering without significant loss of material quality and mass, and without uncontrolled or significant pollution emissions. The closed-loop approach of C\&D waste represents an ideal system which may be difficult to achieve, but it provides a goal for the construction industry to improve the current practices of construction related activities.

\section{Commercial Practices in Australia and Germany}

Governments all over the world have developed regulations and legislations to positively impact on the re-use of construction materials and other products derived from the C\&D waste stream [1]. While there is the common goal of reducing the "energy and emission associated with building demolition and transport to landfills of materials that would not currently be recycled and reduced" [18, p. 204], the way this is realised in varying degrees can look very different across different countries or jurisdictions.

The general practice regarding C\&D waste management is to remove the waste from the construction site for disposal or recycling elsewhere; there is usually not a lot of re-use onsite. What happens to the waste after removal of course, takes different forms. This can encompass a simple disposing in landfill, removing it to a waste separation company, or pre-sorting and then transporting the $C \& D$ waste to a specialised recycling facility. These specialised operators accept pre-sorted waste such as brick and concrete waste only and focus their operations on recycling. There are also options involving mobile recycling units which can be hired out and allow recycling directly onsite. The recycled material is then transported to other places. Sometimes for example in road construction; it might be used directly on the site again. This kind of onsite reuse is however the exception. Generally, recycled materials and products are offered on the market by the recycling facilities to be used elsewhere.

The main difference between the Australian and German C\&D waste management processes appears to be in the common utilisation of separate salvaging operators in Germany. These companies collect the C\&D waste from the construction sites or get them delivered by the builders, and then pass on the useable components of it to the C\&D recycling facilities. In Germany, there 
appears to also be a far greater rate of pre-sorting of C\&D waste on the construction sites than in Australia. In Australia on the other hand, mixed waste facilities fill the role of the German salvagers by also accepting unsorted C\&D waste, and sorting it into its recyclable and non-recyclable components. The mixed-waste facilities might also recycle the sorted C\&D waste on their own sites, contrary to German salvagers who will pass it on to specialised recycling facilities.

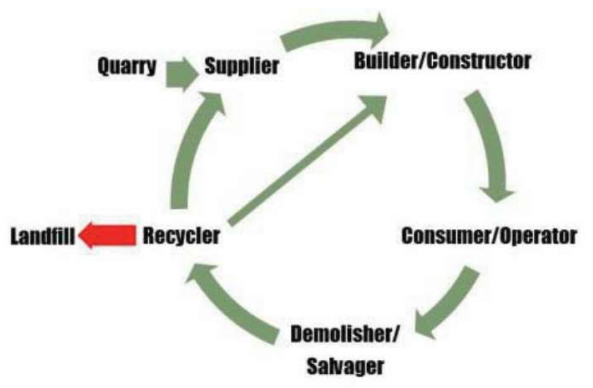

Figure 2. A Life Cycle Model of the Australia C\&D Waste Recycling Approach

When examining the life cycle of Australian C\&D waste recycling, it can be noted that there is a much stronger focus on landfill than it is the case in Germany. One reason for this difference is strong European legislation attempting to eliminate landfills. Another reason might be found in the pricing structure, which is of course partially influenced by legislation such as levies on landfill in some Australian states, this will be examined in more detail in the following section. Figure 2 illustrates the Australian C\&D waste recycling approach.

In Germany, the life cycle of C\&D waste recycling has a far lesser focus on landfill disposal, indeed landfills are partially quarried to comply with European regulations and recycled materials are used to backfill empty quarries. Figure 3 illustrates the German C\&D waste recycling approach.

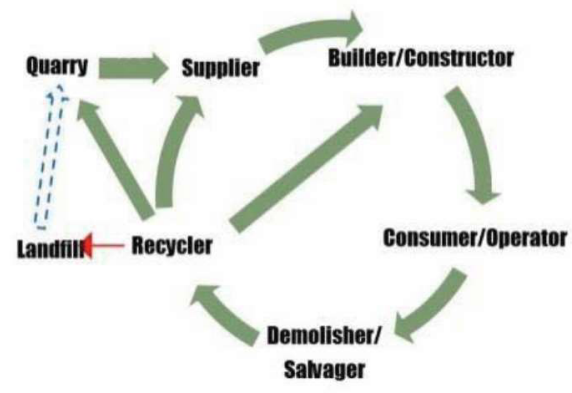

Figure 3. A Life Cycle Model of the German C\&D Waste Recycling Approach
In a series of interviews conducted, we found that the Australian, in particular New South Wales (NSW), construction industry is much more willing to use recycled C\&D waste materials, partially due to a lack of easily accessible virgin materials, while there is a great reluctance on the German side; which seems to be slightly contradictory to the fact that there is a higher recycling rate in German than Australia (and NSW).

\section{Case Study of Australian and German C\&D waste facilities}

This section will introduce a case study for an Australian and a German C\&D waste recycling facility. It is important to note that the actual technology used for sorting and recycling is the same. This might include sieves, crushers, water bath and magnets. However, as previously mentioned, the process in the chain appears to be different in terms of which stakeholder performs which task. Hence the C\&D waste management process will be considered as a supply chain along which the waste is generated either as supply for new materials or products that are based on it, or is disposed as landfill. According to the Australian C\&D Waste Status Report [8], countries like the Netherlands produce virtually no landfill from C\&D waste; everything is re-used or recycled in some future construction process. This is quite remarkable. Both Germany and Australia are still quite some way from this. In Australia, approximately $57 \%$ of C\&D waste was recycled nationally in 2006-07 [8]. There is a high variability in the recycling rates across the country. Since the Australian case study looks at a NSW facility, it is worth mentioning that for the same period $67 \%$ of C\&D waste was recycled in NSW. These rates have since increased; however, 2006-07 data will be used since these are the most comprehensive data sets available [8]. For a similar period, the nationwide recovery rate of $C \& D$ waste in Germany was more than $86 \%$ [8].

\subsection{Australia}

The mixed C\&D waste facility Brandown in Sydney's south-west is a privately owned and operated Resource Recovery Centre, General Solid Waste (Non Putrescible) Landfill and Quarry. They have a C\&D waste recycling facility onsite, and ensure that anything that is recyclable in the C\&D waste delivered is separated and made available as a resource ${ }^{2}$. Brandown recycling has two streams of incoming C\&D waste; a mixed stream which

\footnotetext{
${ }^{2}$ http://www.brandown.com.au/
} 
includes "anything" except asbestos and a recyclable C\&D waste stream. The former is sorted to separate reusable construction waste going to the recycling facility from residual waste, which is being deposited to landfill. Due to the considerably high NSW landfill levy, the prices for the landfill component are relatively high. It would be interesting to see if the recycling rates of C\&D waste have risen in relation to the rising levy. In this paper, the focus will however be on current charges and how they might impact on recycling rates.

Table 1. Brandown Waste Disposal Charges

\begin{tabular}{lc}
\hline Waste Type & \$ per Tonne \\
\hline C1 & 13 \\
C2 & 22 \\
C3 & 50 \\
MM1 & 22 \\
MM2 & 196 \\
MW & 196 \\
\hline
\end{tabular}

Brandown's charges ${ }^{3}$ as of $1^{\text {st }}$ July 2013 are examined in more detail. Selected items were chosen, which can be related to similar items in the German case study for the purpose of comparison. Prices are given for the following waste or recyclable materials: C1 (small pieces with no inclusion), C2 (medium pieces with a small amount of inclusion), C3 (large pieces with a small amount of inclusion), MM1 (mixed masonry: brick and concrete, small with no inclusion), MM2 (mixed masonry: brick and concrete, with inclusions), MW (Mixed/general waste, recyclable or nonrecycable). Table 1 summarises Brandown's prices for these categories of waste.

\subsection{Germany}

As mentioned before, in Germany C\&D waste is usually pre-separated in different bins on site. Salvaging companies might accept mixed waste, but since it is very highly priced, sorting takes preference on most construction sites. A pricelist including mixed waste prices will be provided in this section, however, the case study focused on a C\&D waste recycling facility, since mixed waste $C \& D$ waste recycling facilities are very uncommon in Germany.

The Recycling and Sanierung Thale GmbH (RST) is a C\&D recycling facility in north-eastern Germany, in the Harz Mountains. They have three streams of C\&D waste treatment: high-pressure soil washing, deposit for dangerous and non-dangerous waste, and a C\&D

\footnotetext{
${ }^{3}$ Available on their website (footnote 1 )
}

recycling facility. RST accepts sorted waste only. The waste is then separated further if necessary by washing, sieving and so on. It is recycled by the usual methods such as crushing and sieving. The technology used for these operations is almost identical to the recycling machinery used at Brandown, often it has been bought from the same European suppliers.

Table 2. RST and other local Waste Disposal Charges

\begin{tabular}{lc}
\hline Waste Type & $\begin{array}{c}\text { EUR per } \\
\text { Tonne }\end{array}$ \\
\hline C1 & 6 \\
C2 & 8 \\
C3 & 11 \\
MM1 & 16 \\
MM2 & 24 \\
MW & 135 \\
\hline
\end{tabular}

RST's prices do not include mixed waste, since they do not accept this type of waste. Prices for C\&D waste was directly taken from RST's website ${ }^{4}$, mixed waste prices were retrieved from a web database ${ }^{5}$ containing waste disposal prices for the area of Thale. The categories are similar to the categories defined for the Brandown case study.

\subsection{Comparison}

There are two aspects along which one can compare the C\&D waste recycling operations in Australia and Germany. Firstly, a comparison can be done by the variations in the life-cycle model between the two countries. This was already done in the previous section on C\&D waste recycling practices. Secondly, the different pricing structures and what effect they might have on the actual recycling rates can be examined more closely.

As previously mentioned, high recycling rates are strongly linked to legislative incentives. However, could the higher recycling rates in Germany in part also be explained by the pricing structure as shown in each case study? It is assumed that the structure examined in the following, can be seen as indicative to the Australian ${ }^{6}$ and German situations. Can it be assumed that the larger the difference between the prices for mixed/general waste and recycled waste is, the higher is also the recycling rate? Is there a direct correlation between

\footnotetext{
${ }^{4} 2013$ Pricelist on www.rst-thale.de [viewed on 20.1.2014)

${ }^{5}$ www.abfallscout.de (queried on 20.1.2014)

${ }^{6}$ In particular NSW
} 
recycling and pricing rates? The rates were either taken or derived from statistics in the aforementioned 2011 C\&D waste status report [8]. The price difference was calculated in percentage between general waste and each type of recyclable waste, thus showing the savings attainable for each case study (representative for the countries the case studies were situated in) when recycling $C \& D$ waste instead of directly depositing it into landfill. Table 3 summarises these statistics and Figure 4 compares the Australian and German savings.

Table 3. Savings made when recycling different types of

\begin{tabular}{ccc}
\hline $\begin{array}{c}\text { Type } \\
\text { of } \\
\text { Waste }\end{array}$ & $\begin{array}{c}\text { Australian } \\
\text { Savings to MW } \\
\text { in \% }\end{array}$ & $\begin{array}{c}\text { German } \\
\text { Savings to MW } \\
\text { in \% }\end{array}$ \\
\hline C1 & 93.37 & 95.6 \\
C2 & 88.78 & 94.08 \\
C3 & 74.49 & 91.86 \\
MM1 & 88.78 & 88.09 \\
MM2 & 0 & 82.23 \\
MW & 0 & 0 \\
\hline
\end{tabular}

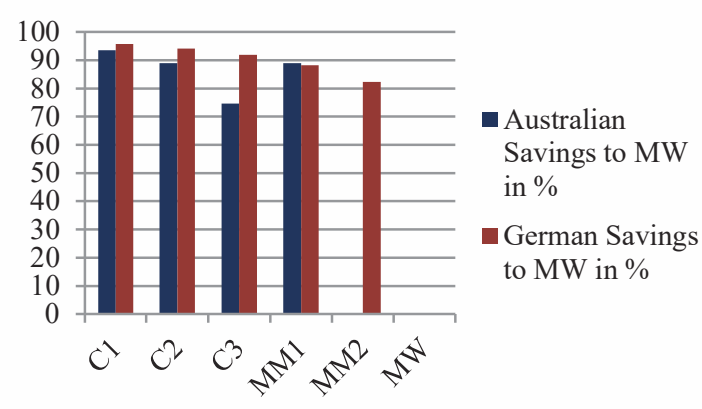

Figure 4. Savings compared to mixed waste

As can be seen in table and figure, mixed masonry with inclusions does not give any economic benefit as compared to general and mixed waste in Australia. The saving are at least the same or higher in Germany.

The percentage of savings is also reflected in recycling rates, which are $57 \%$ nationwide in Australia, $67 \%$ in NSW (as derived from data in [7]) and $86 \%$ in Germany. If compared to the average cost savings to mixed waste of $57 \%$ in Australia and $75 \%$ in Germany, there is a clear correlation between pricing structures and recycling rates. This is shown in Figure 5.

\section{Conclusions}

There are great opportunities for C\&D waste to be recycled and reused. The paper discusses issues and

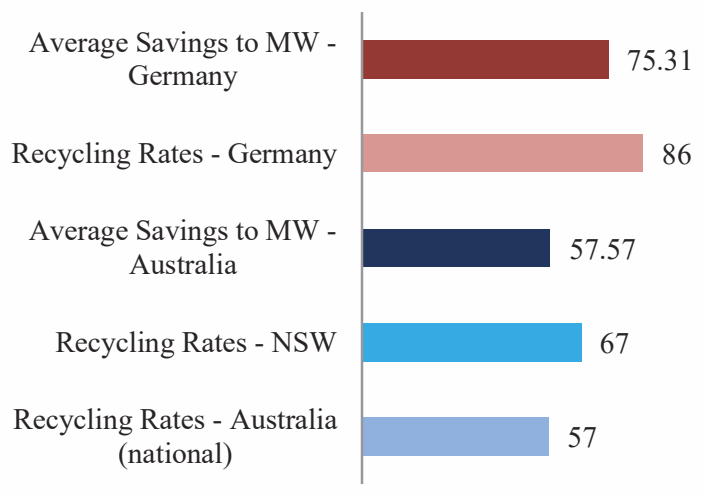

Figure 5. Relationship between average pricing and recycling rates

challenges of $C \& D$ waste in the construction industry and presents a closed-loop model for C\&D waste as an approach to achieve the goal of zero waste. The closed-loop model may be ideal but it is possible and advantages in maintaining the sustainability of the natural resources on the environment.

The paper also presents results of a comparative study of C\&D waste management processes between Australia and Germany. The results reveal that the German practice has a higher waste recovery rate than the Australian practice. The pre-sorting and separating facilities on construction or demolition site in Germany place an important role in achieving high recovery rate of waste for recycling and reuse. This aligns with the literature review that high recycling rates for materials are achieved when materials are captured closer to the source before mixing with other wastes. Whilst there was insufficient pre-sorting and separating facilities in Australia there is therefore a higher risk of cross-contamination that may hamper the recovery of useful materials in the $C \& D$ waste.

The closed-loop model may be viewed as an ideal system but it represents a goal for the construction industry to raise awareness among professional to achieve better practices. Ultimately the concept can encourage the construction industry to rethink the design and construction by taking into consideration for dismantling and reuse at the end of a building's life at an outset and the use of processes and materials on the construction and demolition project and to innovate to meet the challenge of sustainable development. 


\section{References}

[1] Australian Government, Department of Sustainability, Environment, Water, Population and Communities. Construction and Demolition Waste Guide - Recycling and Re-use across the Supply Chain. Commonwealth of Australia, 2011 .

[2] Environmental Protection Agency. Waste Guidelines, EPA 842/09, Adelaide, SA, Australia, 2009.

[3] Marrero, M., Solis-Guzman, J., Alonso, B.M., Osuna-Rodriguez, M. \& Ramirez-de-Arellano, A. Demolition waste management in Spanish legislation, The Open Construction and Building Technology Journal, 5:162-173, 2011.

[4] Ekanayake, L.L. \& Ofori, G. Building waste assessment score: design-based tool. Building and Environment, 39(7):851-861, 2004.

[5] Esin, T. \& Cosgun, N. A study conducted to reduce construction waste generation in Turkey. Building and Environment, 42(4):1667-1674, 2007.

[6] Letcher, T. \& Vallero, D. Waste: A handbook for management, Elsevier, Oxford, UK, 2011.

[7] ABS. Australia's environment: Issues and trends 4613.0, Australian Bureau of Statistics, January, 2010 .

[8] Hyder Consulting, Encycle Consulting \& Sustainable Resource Solutions. Construction and Demolition Waste Status Report. Department of Sustainability, Environment, Water, Population and Communities, Queensland Department of Environment and Resource Management, February 2011.

[9] Marie, I. \& Quiasrawi, H. Closed-loop recycling of recycled concrete aggregates. Journal of Cleaner Production, 37:243-248, 2012.

[10] Dolan, P.J., Lampo, R.G. \& Dearborn, J.C. Concepts for reuse and recycling of construction and demolition waste, US ACERL Technical Report 99/58, US Army Corps of Engineers, 1999.

[11] Osmani, M., Glass, J. \& Price, A. Architect and contractor attitudes to waste minimization, In Proceedings of the Institution of Civil Engineers, May:65-72, 2006.

[12] Yuan, H. \& Shen, L. Trend of the research on construction \& demolition waste management. Waste Management, 31:670-679, 2011.

[13] Gambin, N., Leo, C. \& Rahman, A. Management of C \& D waste. Journal of Environmental Research \& Development, 5(1):96-104, 2010.

[14] Halliday, S. Sustainable construction, Butterworth-Heinemann. Sydney, Australia, 2008.

[15] Calkins, M. Materials for sustainable sites, John Wiley \& Sons, New Jersey, US, 2009.

[16] Braungart, M., McDonough, W. \& Bollinger, A. Cradle-to-cradle design: creating healthy emissions - a strategy for eco-effective product and system design. Journal of Cleaner Production, 15:1337-1348, 2007.

[17] Sassi, P. Defining closed-loop material cycle construction. Building Research \& Information, 36(5):509-519, 2008.

[18] Trusty B. W. Renovating vs. Building New - The Environmental Merits. OECD.OECD/IEA Joint Workshop on Sustainable Buildings: Towards Sustainable use of Building Stock, Tokyo, January 2004. 